\title{
Correction to: A Late Jurassic (Kimmeridgian-early Tithonian) fish fauna of the Eperkés-hegy (Olaszfalu, Bakony Mts., Hungary): the oldest record of Notidanodon Cappetta, 1975 and a short revision of Mesozoic Hexanchidae
}

\author{
Márton Szabó ${ }^{1,2}$ (1)
}

Published online: 18 May 2019

(C) Senckenberg Gesellschaft für Naturforschung and Springer-Verlag GmbH Germany, part of Springer Nature 2019

Correction to: Palaeobio Palaeoenv

https://doi.org/10.1007/s12549-018-00368-x

Due to typesetting error, the scale bars for Figs. 2, 3 and 6 were missing in the online article. Tables 2 and 3 also contained mistakes. The correct figures and tables are shown here.

Márton Szabó

szabo.marton.pisces@gmail.com

1 Department of Palaeontology, Eötvös University, Pázmány Péter sétány $1 / \mathrm{C}$, Budapest 1117 , Hungary

2 Department of Paleontology and Geology, Hungarian Natural History Museum, Ludovika tér 2, Budapest 1083, Hungary 
Fig. 2 Notidanodon sp. a Lower anterolateral tooth (VER

2018.359.) in lingual view and $\mathbf{b}$ in labial view. c Lower anterolateral tooth (VER 2018.360.) in lingual view, $\mathbf{d}$ in mesial, $\mathbf{e}$ in labial view and $\mathbf{f}$ in apical view. Scale bars: $\mathbf{a}$ and $\mathbf{b}$ $5 \mathrm{~mm} ; \mathbf{c}-\mathbf{f} 10 \mathrm{~mm}$
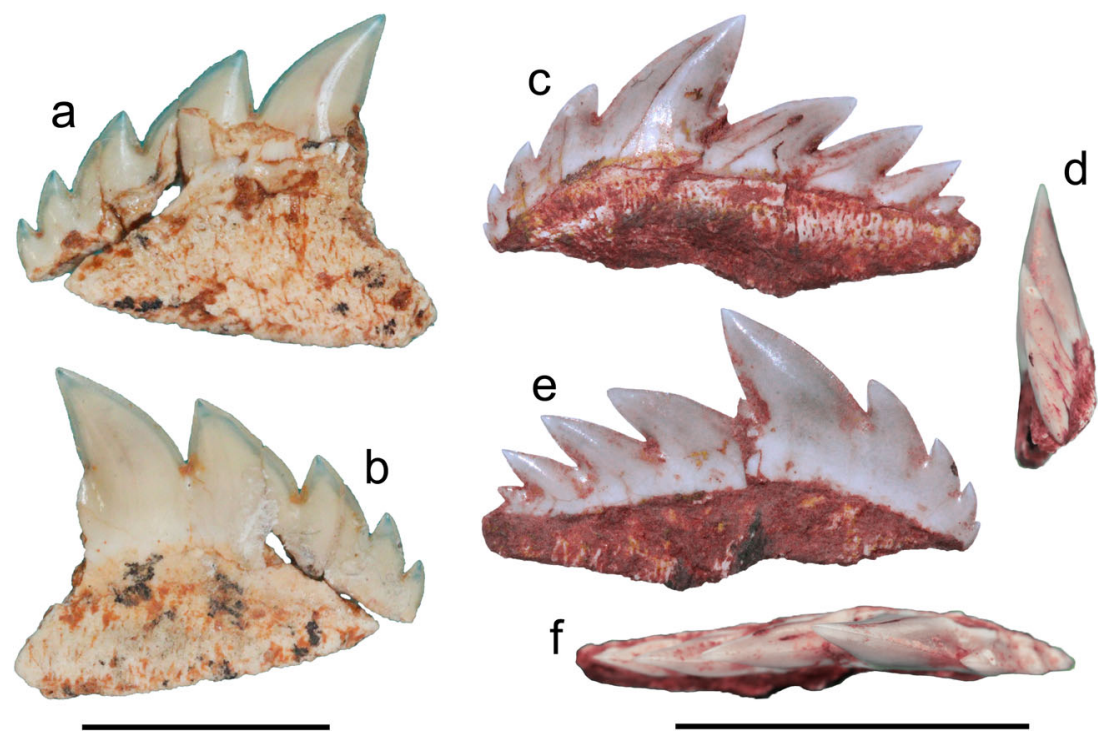
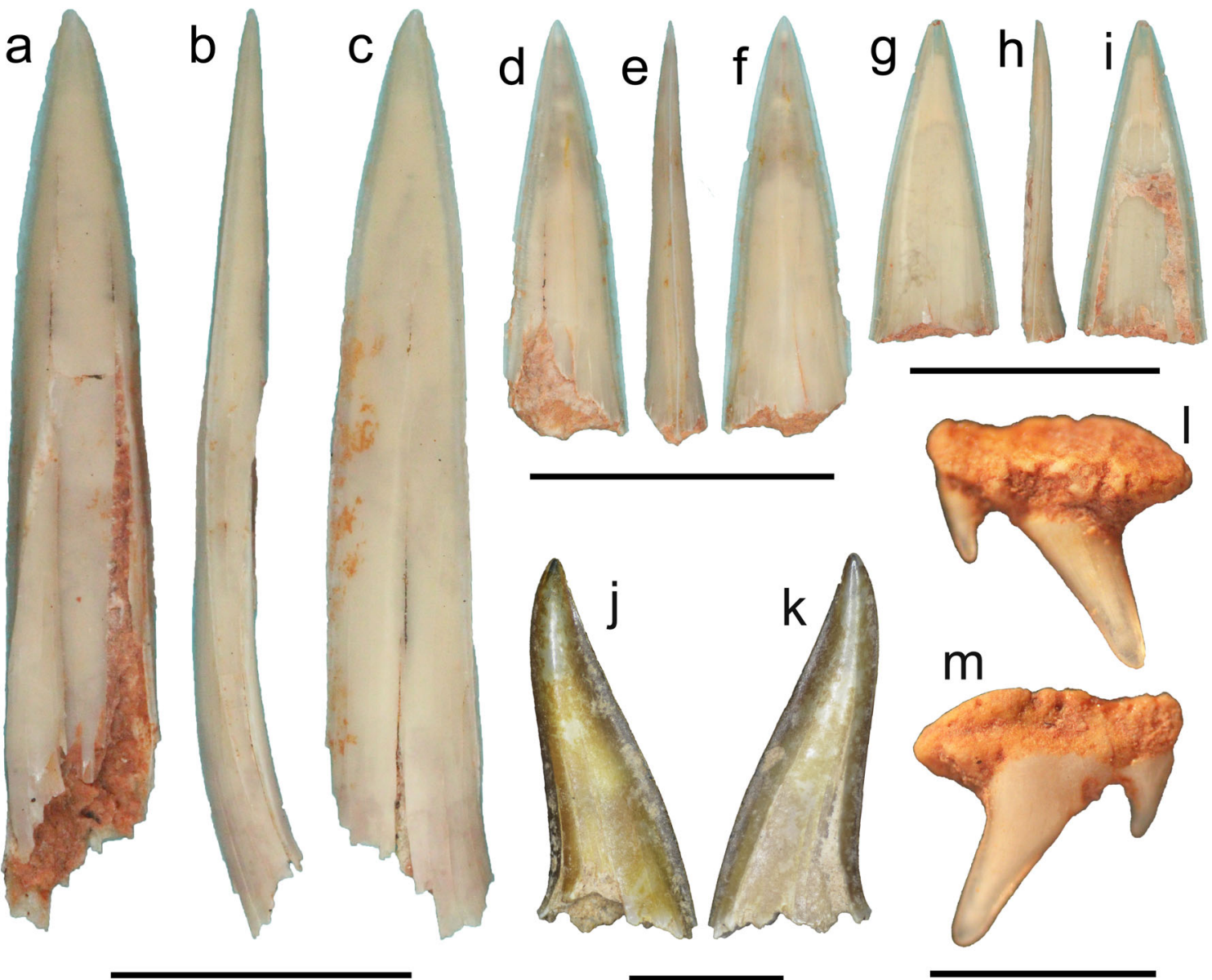

Fig. 3 a-k Sphenodus sp. a VER 2018.362. in lingual view, b in profile view and $\mathbf{c}$ in labial view. d VER 2018.363. in lingual view, $\mathbf{e}$ in profile view and $\mathbf{f}$ in labial view. $\mathbf{g}$ VER 2018.367. in lingual view, $\mathbf{h}$ in profile

view and $\mathbf{i}$ in labial view. $\mathbf{j}$ and $\mathbf{k}$ VER 2018.366. in two different views. I and $\mathbf{m}$ Synechodontiformes indet. I VER 2018.361. in lingual view and $\mathbf{m}$ in labial view. Scale bars: a-i $10 \mathrm{~mm}$; $\mathbf{j}-\mathbf{m} 2 \mathrm{~mm}$ 

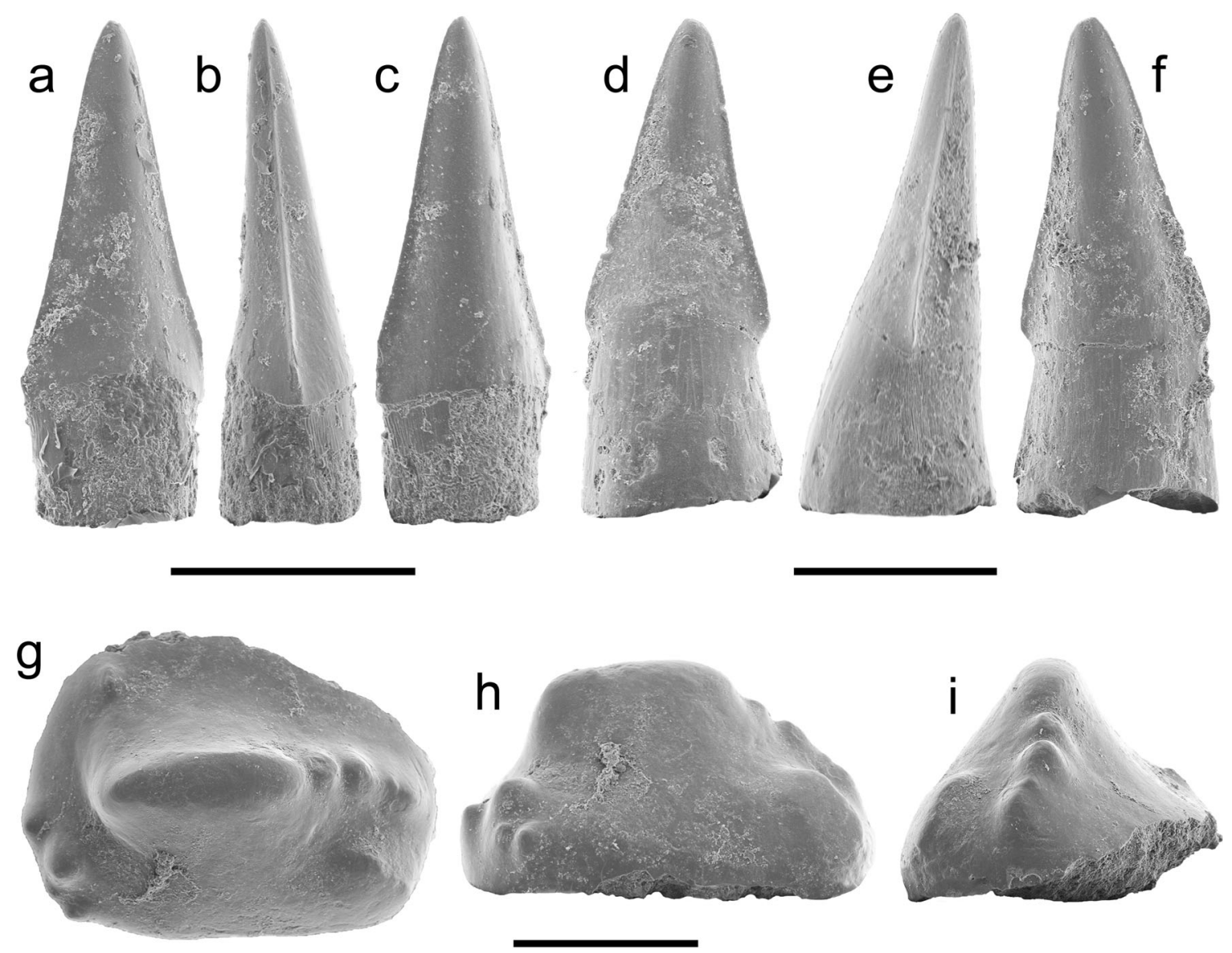

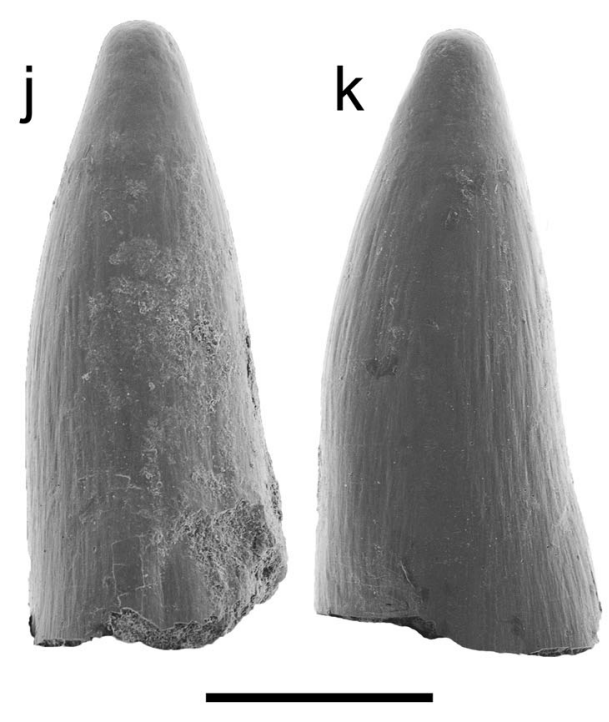

Fig. 6 a-f Caturus sp. a VER 2018.381. in lingual view; b in profile view; $\mathbf{c}$ in labial view. d VER 2018.382. in labial view; $\mathbf{e}$ in profile view; $\mathbf{f}$ in lingual view. g-l Actinopterygii indet. remains $\mathbf{g}-\mathbf{i}$ VER 2018.384. in

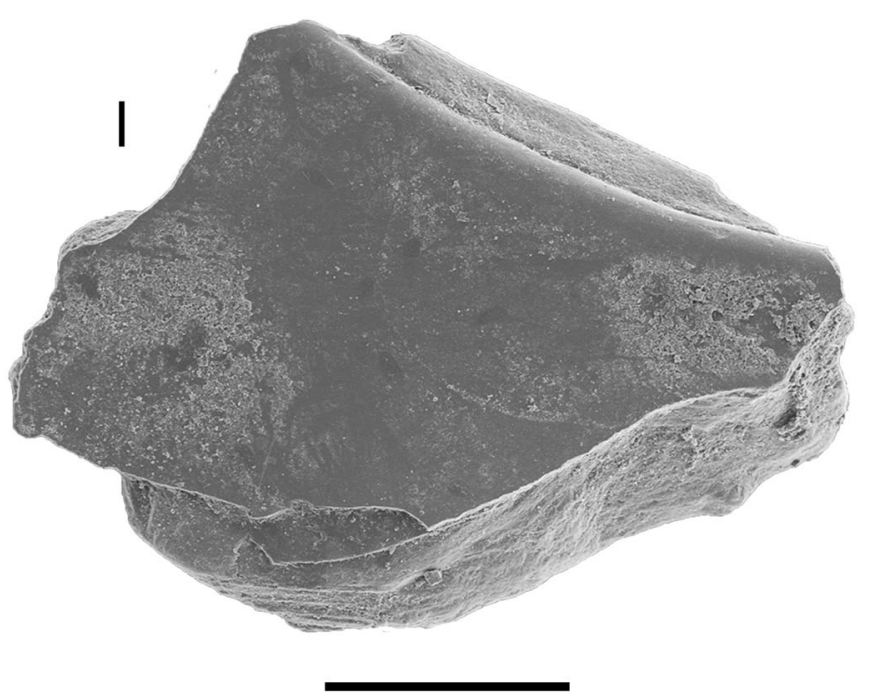

three different views. $\mathbf{j}$ and $\mathbf{k}$ VER 2018.385. in two different views. I VER 2018.386. in external view. Scale bars, $500 \mu \mathrm{m}$ 


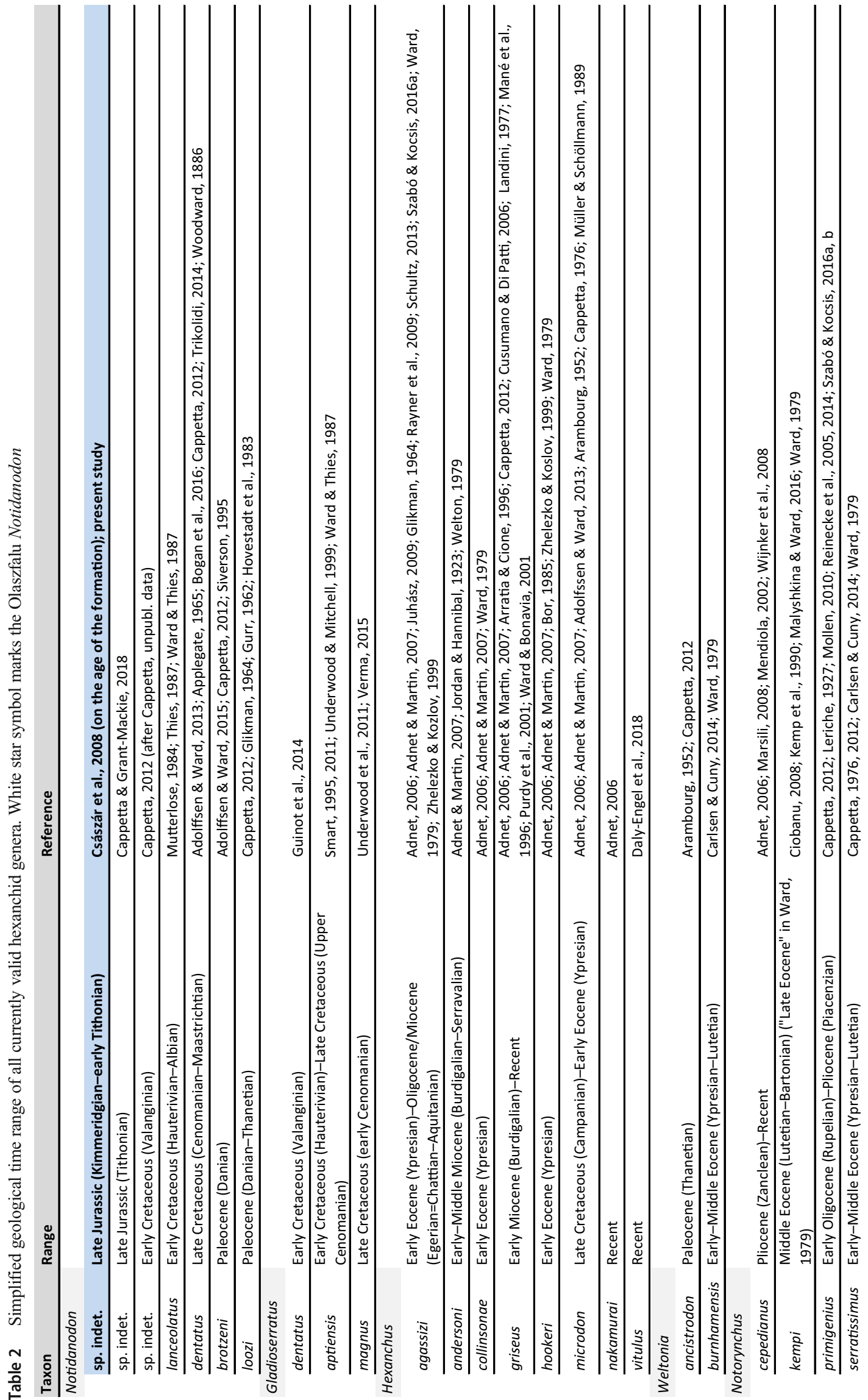


Table 2 (continued)

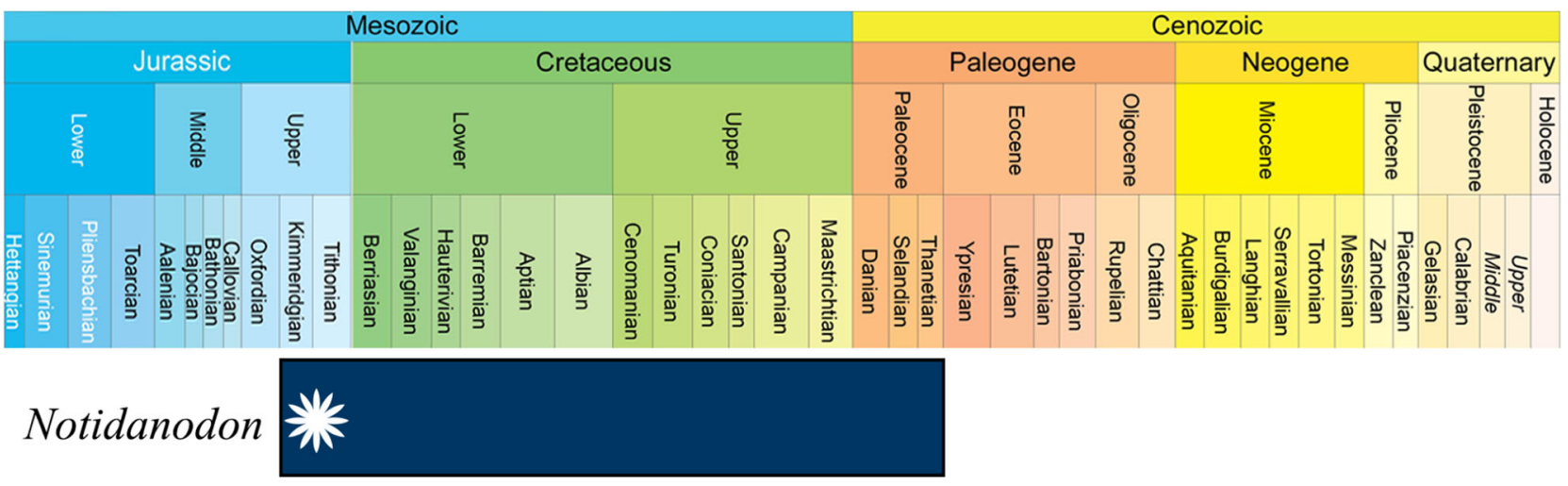

Gladioserratus

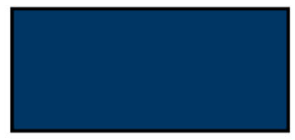

Hexanchus

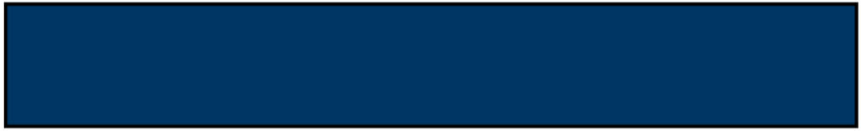

Weltonia

Notorynchus 


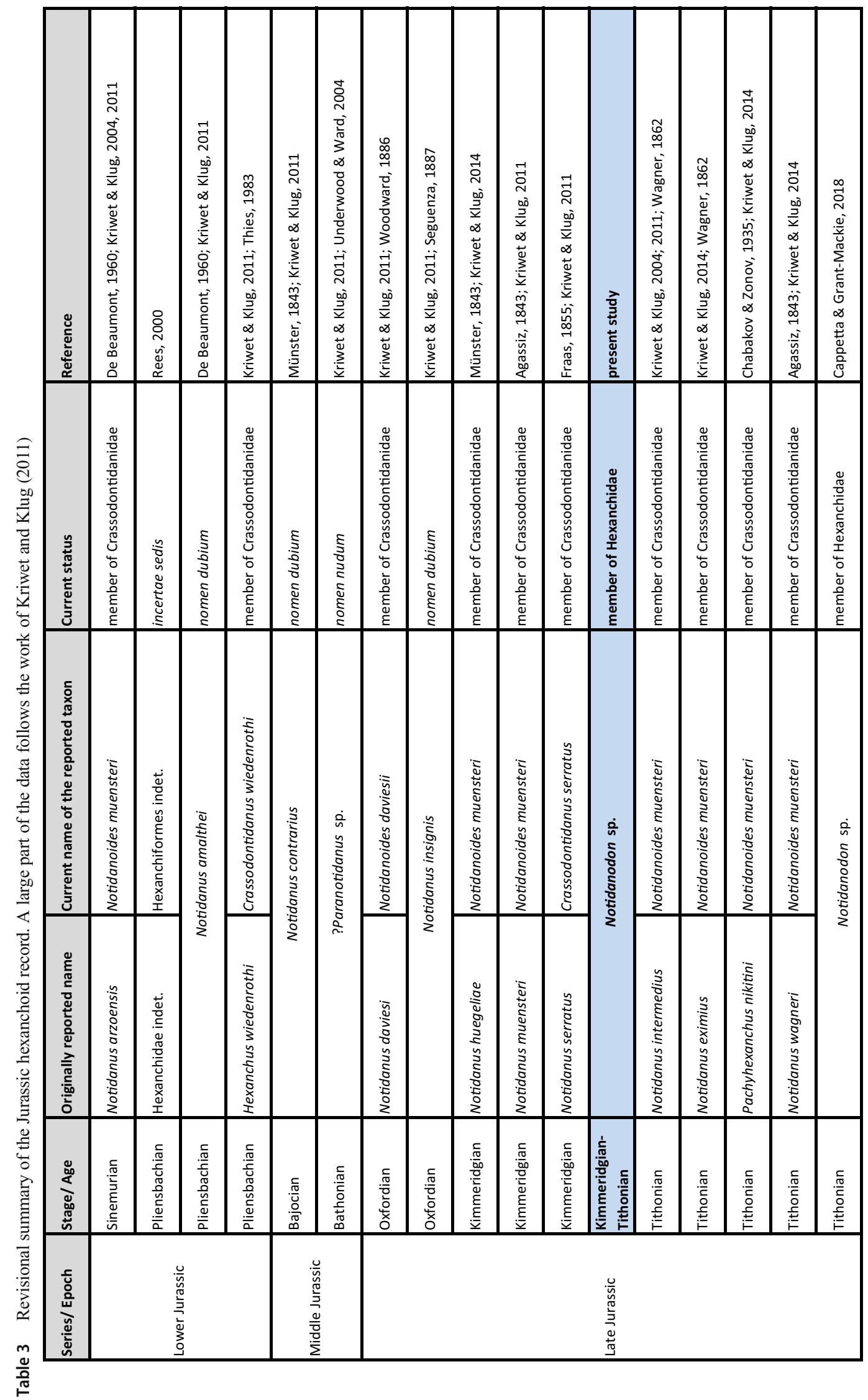


The Publisher regrets this error.

The original article has been corrected.
Publisher's note Springer Nature remains neutral with regard to jurisdictional claims in published maps and institutional affiliations. 